\title{
Applications of Mass Stabilization at Baltic Sea Region
}

\author{
Juha Forsman ${ }^{1}$, Tommi Marjamäki², Harri Jyrävä3 ${ }^{3}$, Noora Lindroos ${ }^{4}$, Merja Autiola ${ }^{5}$ \\ ${ }^{1,2}$ Ramboll Finland Oy, Espoo, Finland \\ ${ }^{3,4,5}$ Ramboll Finland Oy, Luopioinen, Finland \\ E-mail:1,2n.n@ramboll.fi (corresponding author)
}

\begin{abstract}
Mass stabilization is soil improvement method to increase the strength and stiffness of soft soils (e.g. peat, mud, clay, silt) by using an admixed binder agent. In the demanding soil conditions of Baltic Sea region shore line and interior soft soil areas, cost effective soil improvement methods are needed in the foundation engineering and earth construction. Methods are also needed in the handling of soft and/or contaminated sediments (clay, mud, etc.), which are not allowed for off shore dumping. For these applications, mass stabilization has been proven to be a cost effective method and the effectiveness of mass stabilization has been demonstrated in laboratory and in field conditions during last decades. Especially good results have been reached with contaminated dredged sediments, which enable harbours to reuse sediments for construction. Better cost effectiveness has been achieved when by-products or waste materials have been utilized as a binder. Numerous mass stabilization projects have been carried out around the word and in the Nordic countries since beginning of 1990's. In this article is presented: the principles of mass stabilization method, case examples of using mass stabilization in harbour and road construction projects, utilization of by-product or waste based binders and the cost effectiveness of that kind of binders.
\end{abstract}

Keywords: deep mixing, mass stabilization, contaminated sediments, dredged sediments, fly ash, oil shale ash, soil improvement.

Conference topic: Geoenvironmental engineering.

\section{Introduction}

The mass stabilization method was developed in Finland in the beginning of the 1990s. Starting from the year 1993, the first large applications included mass stabilization of the areas with peat during some road and railway line construction works in Finland and Sweden. Since 1996, mass stabilization has been applied for processing soft and/or polluted dredged sediments allowing for their further utilization as construction material in port development construction works. The past decades have brought fast development of the mass stabilization equipment, binders and various new applications (Lahtinen, Niutanen 2009; Maijala et al. 2009).

The method has been implemented in numerous countries in various infrastructure and environmental engineering applications. Estimation is that only with mass stabilization equipment produced by ALLU Stamix ${ }^{\circledR}$ has been conducted mass stabilization projects in 25-30 countries proving it to be an economical and eco-efficient solution.

The application of mass stabilization techniques alters the technical (Fig. 1) and environmental properties of soft soil in a way that makes it possible to construct on top of the stabilized soil or utilize it as filling or construction material (Figs 3 and 4). The applications of the method can be divided into 1) mass stabilization of soft soils on site (in situ) and 2) stabilization of excavated soft soils or dredged sediments (clay, mud, etc.) off site (ex situ).
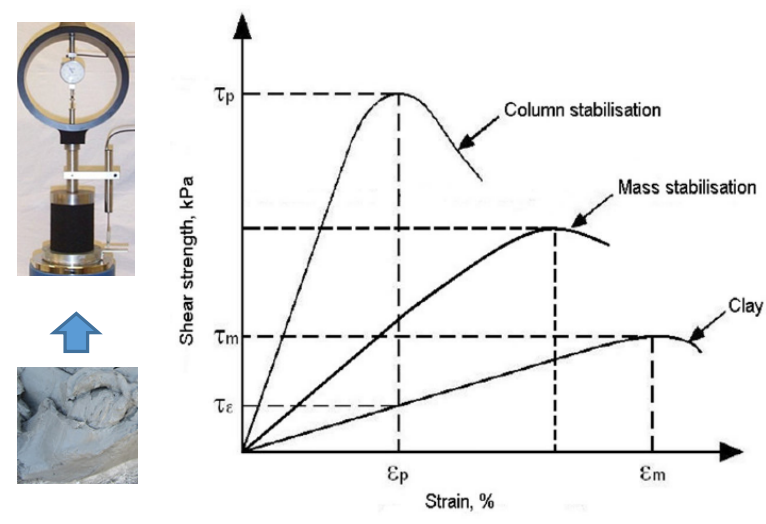

Fig. 1. The impact of stabilization on strength and stiffness of soft clay. On the left side (down) is soft clay and stabilised clay in 1-axial compression test (up)

(Source: Forsman et al. 2015a)

\section{Mass stabilization method}

The intent of mass stabilization is, by using an admixed binder agent, to increase the strength of the soft soil layers (such as clay, mud and peat) to such an extent as is required in design. In "Nordic stabilization method", mass stabilization is carried out by using dry binder(s). With the current equipment, the attachment of a mixing unit to an excavator, allows for carrying out stabilization to the depth of 7-8 meters, providing the conditions are favourable. The working capacity of a mass stabilization system depends on the soil material to be stabilized, but in general it varies between fifty and two hun-

(C) 2016 The Authors. Published by VGTU Press. This is an open-access article distributed under the terms of the Creative Commons Attribution License, which permits unrestricted use, distribution, and reproduction in any medium, provided the original author and source are credited. 
dred cubic meters of stabilized soil per hour and per one mass stabilization unit $\left(\approx 50-200 \mathrm{~m}^{3}-\right.$ stabilized soil / h / unit). (Forsman et al. 2015b)

Mass stabilization affects the environmental properties of the stabilized material. Mass stabilization of excavated or dredged soft soil masses enables their utilization at the construction site as a filling or construction material. In the case of soft or contaminated excavated soils, the use of mass stabilization results in considerable advantages:

1. Soft soil masses can be processed, which allows for avoiding the dumping of low quality soil masses to landfills, and reducing demands for virginal aggregates together with the associated needs for transportation.

2. Stabilization of contaminated soils may lead to reduced solubility of heavy metals, which allows for processing and utilization of the soil, thus eliminating the need of transportation to contaminated soils landfill.

Mass stabilization can be used in versatile applications as a subgrade improvement method and as a lowquality soil processing method - applications include:

- roads, streets and railways,

- municipal engineering,

- harbours and sea routes (fairways),

- landscaping sites (e.g. parks),

- environmental protection structures,

- mining areas,

- landfills and waste treatment areas,

- industrial and commercial areas,

- housing construction areas and

- flood protection.

\section{Mass Stabilization guidebooks}

Mass Stabilization Handbook was completed in 2015 (Forsman et al. 2015a). Its objective is to promote the use of the stabilization method. The manual focuses on mass stabilization applications carried out with the equipment presented in Figure 2. It does not address process stabilization. However, some of the principles set out in the handbook can also be applied to process stabilization applications (in process stabilization soft soil and binder is fed to continuous mixer or power mixer to stabilize the soil ex situ). The manual is designed to serve the needs of all the parties involved in a stabilization project (developer, ground investigator, laboratory, designer, contractor, quality controller, authorities, binder suppliers, and researchers).

The manual offers practical instructions on issues concerning ground survey, design, construction and quality control. The main principles of the mass stabilization method and the differences in comparison to other alternative solutions are described. The manual describes a variety of previously implemented technical and environmental applications, which have yielded significant positive experience.

Sustainable Management of Contaminated Sediments guideline (SMOCS 2013) provides, based on a sustainability approach, comprehensive guidance starting from a description of "what to do" in the different phases during the whole process of a contaminated sediments project and continuing to descriptions of "how to do" in the different phases and decision situations. Some examples of use and disposal of dredged stabilized sediments are presented in Figure 4.

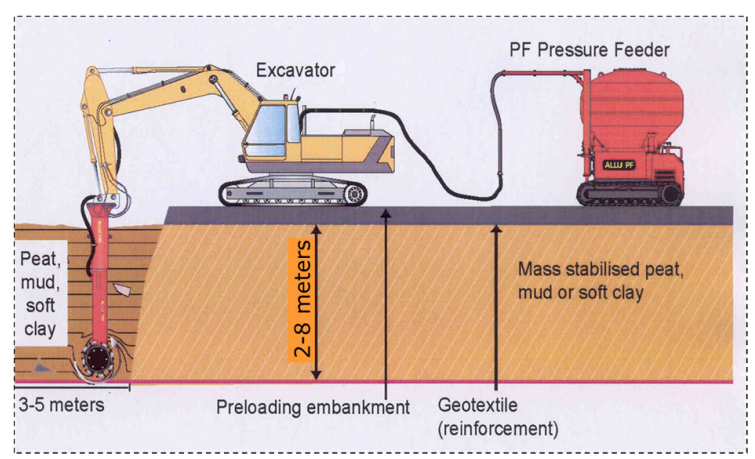

Fig. 2. Mass stabilization equipment. Elements such as a mixing unit, pressure feeder and the control \& data collecting unit are attached to the excavator (Source: Forsman et al. 2015a)

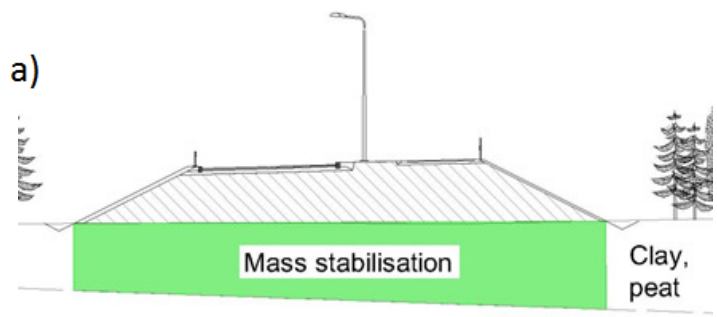

b)

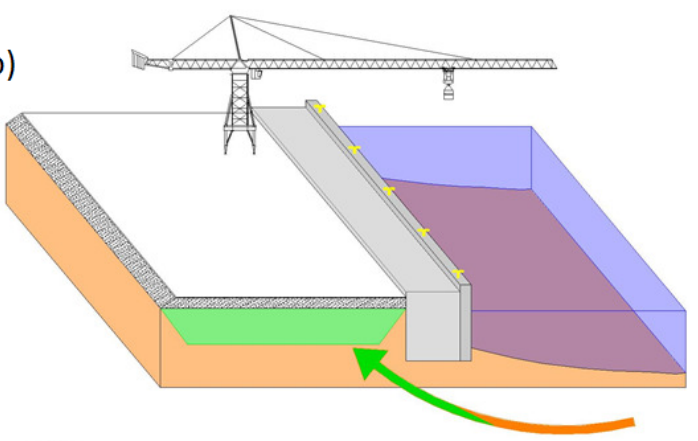

c)

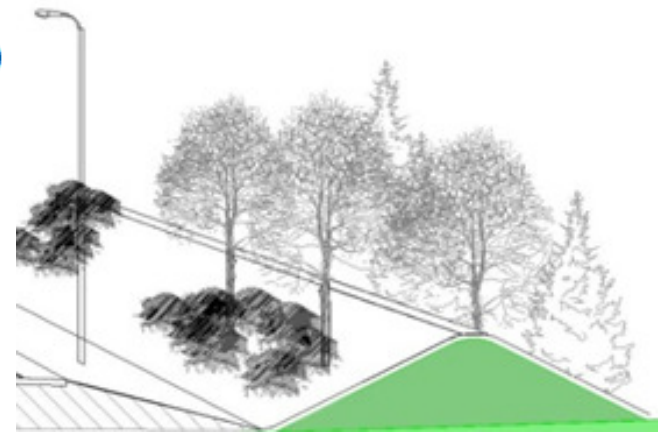

Fig. 3. Some mass stabilization applications: a) road or railway embankment over in situ mass stabilized soil, b) port field and c) noise barrier filling with ex situ mass stabilized material (Source: Forsman et al. 2015a) 


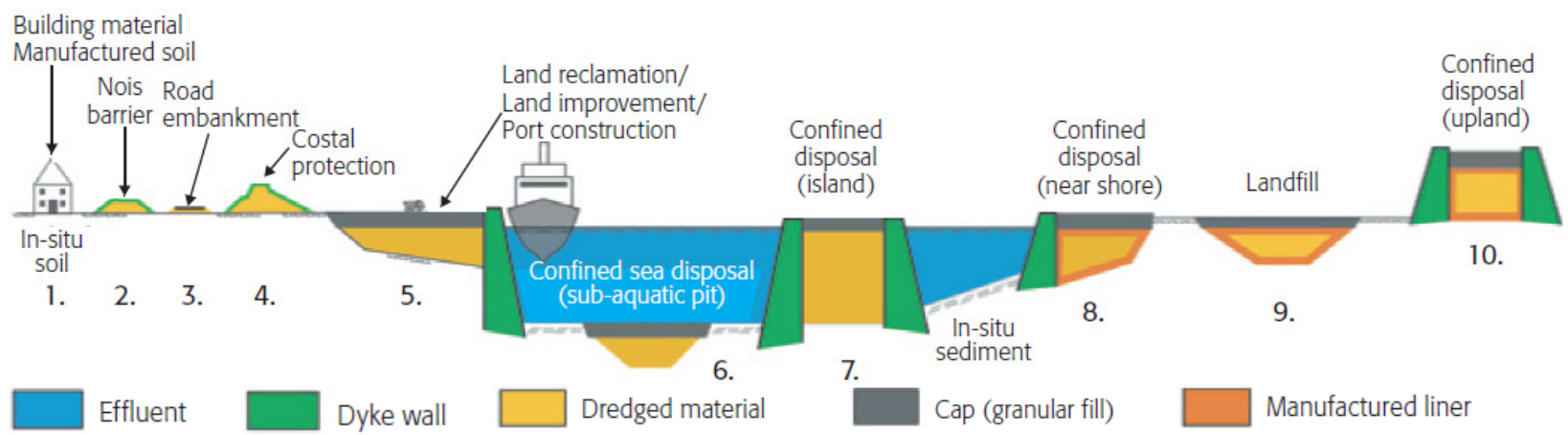

Fig. 4. Examples of the use and disposal of dredged mass stabilized sediments. Provided for illustrative purposes only, an artist's impression of the proposed Oakajee deep-water iron ore port, in Western Australia (Source: SMOCS 2013)

\section{Handling of dredged sediments}

Marine sediments in the coastal areas are often contaminated as a consequence of industrial and port activities, as well as the influence of cities located there. Construction activities and reclamation of shore line require dredging and handling of contaminated sediments since the level of contamination inhibit offshore dumping of dredged sediments.

Based on their technical properties, most of these dredged soft and watery sediments (clay, mud, etc.) are regarded as too poor quality material for earth construction purposes. Mass stabilization technology has been applied to improve the technical properties of those materials in order to utilize them as construction material. Owing to stabilization, the contamination is encapsulated in a monolithic solid of a high structural integrity. Thus, migration of contaminants is restricted by the decreased surface area exposed to leaching. Economic, sustainable and environmentally safe management of contaminated dredged sediments is a key issue in many construction sites (Lindroos et al. 2012, 2014).

\section{Binders of dredged sediments stabilization}

The development of a proper recipe for mass stabilization of sediments can be challenging. Stabilization of contaminated sediments is highly dependent on sediment matrix, binder materials, contamination and physical conditions such as the water content. Additionally, the development of a cost efficient binder admixture is important because the costs of binder materials are usually the principal part of the total costs of the stabilization process. Some dredged materials are difficult to stabilize and solidify and require the use of multiple binder components. In the case of contaminated dredged sediments the technical challenges are increased by environmental requirements. The contaminants have to be stabilized and/or the dredged material made so solid and impermeable that any leaching or other release of the contaminants into the surrounding environment is impossible.

In the SMOCS project one task was to study both the technical and environmental properties of stabilized contaminated sediments in laboratory. The investigated sediment samples originated from different parts of the
Baltic Sea: from Finland (Kokkola, Helsinki), Poland (Gdynia) and Lithuania (Klaipeda). On the basis of those (and numerous other investigations), can be indicated:

- By using industrial by-products or wastes as binder material, the amount of commercial binder (e.g. cement) can be decreased.

- By using fly ashes and/or gypsum, the binder costs and $\mathrm{CO}_{2}$ emission can be reduced.

-Fly ashes from biomass combustion or oil shale combustion contain free lime and due to that they are reactive (well hardening) as binders.

In case waste materials such as fly ashes are used as binder material, their chemical content and solubility of contaminants have to be known. The utilization of fly ashes as binder material has been proved to be safe to the environment both in laboratory scale and in field tests; the solubility of harmful substances and the hydraulic conductivity are low in mass stabilized soil. (Lindroos et al. 2012, 2014)

\section{Cost effectiveness}

Unit price of the stabilized sediment $\left(€ / \mathrm{m}^{3}\right)$ grows with the increase of the binder amount. Commercial binders (CE-marked products) are pricey and the value of stabilized sediment as a construction material (filling or embankment) is not so high. Because of that, the amount of binder has to be optimized, taking into consideration the requirements set by the utilization site. For example, in case of the West Harbour and the utilization sites of the city of Helsinki, there are several items to be considered, such as the technical demands of the structures, environmental permits for the utilization site, contamination of the sediments, availability of the alternate binder materials, etc. and naturally other solutions for the contaminated sediments and the price of those.

In Finland, environmental permit is needed for stabilization of contaminated sediments and for the use of waste material based binders like fly ash. Waste materials have a high tax (70 €/t since 1.1.2016 in Finland) in case they are not utilized, so the producers of these kinds of waste materials are motivated to offer their material as stabilization binder. 
Replacing cement with fly ash or oil shale ash outstandingly reduces the binder price $\left(€ / \mathrm{m}^{3}\right)$ in the process of sediment stabilization. To obtain good stabilization result, the amount of pure cement needed is normally at least $80-100 \mathrm{~kg} / \mathrm{m}^{3}$ and the binder price is about 8 $10 € / \mathrm{m}^{3}$ for the stabilized sediment. When the amount of cement can be reduced to, e.g. $40 \mathrm{~kg} / \mathrm{m}^{3}$ by adding, e.g. $150 \mathrm{~kg} / \mathrm{m}^{3}$ of fly ash binder, the price of binder mixture can drop to about $4-5 € / \mathrm{m}^{3}$ and the saving in the binder costs can be over 50\%. (Forsman et al. 2015b). In some cases, e.g. in the case of Kokkola Harbour construction, the fly ash was so well hardening (reactive) that cement was not needed in binder recipe (Autiola et al. 2012).

\section{Mass stabilization in harbour construction}

Handling of dredged sediments (clay, mud, etc.) has been done with mass stabilization method e.g. in cases: Port of Hamina (Finland 1996), Sörnäinen shore (Helsinki, Finland 1999), Port of Trondheim (Norway 200102), Öserumviken (Västervik, Sweden 2002), Vuosaari Port (Helsinki, Finland 2004-06), Port of Valencia (Spain, 2004-06), Hammerfest (Norway 2006), Port of Gävle (Sweden, 2009, process stab.), Baerum (Norway 2009), Port of Turku (Finland 2007-09, process stab.), Port of Kokkola (Finland 2008, 2011-12), Uusikaupunki Fairway (Finland 2009-12, 2013-2014), Port of Poole (UK 2013), Rauma Fairway and Sampaanala bay (Finland, 2011-14), Kalasatama area (Helsinki, Finland 2012) and West Harbour area (Helsinki, Finland 201115). The largest of these is the Vuosaari Port where the amount of TBT-contaminated dredged and mass stabilized sediment was 0.5 million $\mathrm{m}^{3}$ (Havukainen et al. 2011). In addition to these there are dozens of cases that have been studied at least in the laboratory scale, and some of which are waiting for construction decision. The case of Kokkola is presented next more thorough.

\section{Case Kokkola Harbour mass stabilization}

Port of Kokkola is one of the largest northern ports in the Baltic Sea (est. 1824). The port is still expanding and developing due to increasing traffic. The most important metal and chemical industry in the Nordic countries is concentrated in Kokkola and the sea area is polluted by emissions from both industry and the city. With funding from project SMOCS, quality and contamination of the sediment in port and fairway were investigated. The sediments have harmful substances at levels which locally cause substantial toxicity harm to benthic community. The principal noxious substances are As, $\mathrm{Cd}, \mathrm{Cu}, \mathrm{Pb}, \mathrm{Hg}, \mathrm{Ni}, \mathrm{Zn}$ and TBT (Autiola et al. 2012).

Both building of new quays and deepening of fairways require dredging of sediment. The dredged sediment was not acceptable for sea dumping, and thus it was decided that the sediment will be mass stabilized in a banked stabilization basin (Fig. 5). The $1^{\text {st }}$ phase of dredging of contaminated sediments $\left(12.500 \mathrm{~m}^{3}\right)$ was done in Silverstone port area (Hopeakivi), where new quay will be built in the future. The dredging was carried out with environmental dredging method (2011).
Before the mass stabilization in the basin, binder selection was made based on laboratory tests (geotechnical properties, strength and its development along time, water permeability and environmental suitability of stabilized soil). The selected binder receipt was cement + fly ash $30+100 \mathrm{~kg} / \mathrm{m}^{3}$. In begin of the mass stabilization work was noticed very intensive hardening. The decision was that no cement is needed and the rest of stabilization was made with pure fly ash binder 150$200 \mathrm{~kg} / \mathrm{m}^{3}$. The fly ash originates from mixed burning of wood, peat, coal and recycled fuels.

The target shear strength was $50 \mathrm{kPa}$. The soundings in the basin proved the average shear strength of unstabilized and stabilized soil to be $15-30 \mathrm{kPa}$ and 200 $500 \mathrm{kPa}$ (after one year hardening). Water permeability of unstabilized and stabilized soil was $10^{-7}-10^{-8} \mathrm{~m} / \mathrm{s}$ and $2-$ $4 \times 10^{-8} \mathrm{~m} / \mathrm{s}$. On the basis of the quality control and quality assurance, conducted during and after stabilization, stabilized masses fulfilled well all requirements (Autiola et al. 2012).

The port is expanding to the sea and in the building of harbour areas is needed millions of cubic meters of filling. With mass stabilization of dredged soft sediments from fairways, the amount of filling can be reached quite fast. The results of the field test in $1^{\text {st }}$ phase will be the base to the handling of the sediments. Transporting of corresponding masses from land would be slow and expensive (Autiola et al. 2012). The next phase of the mass stabilization of the sediments is planned to take place in 2017-2019.

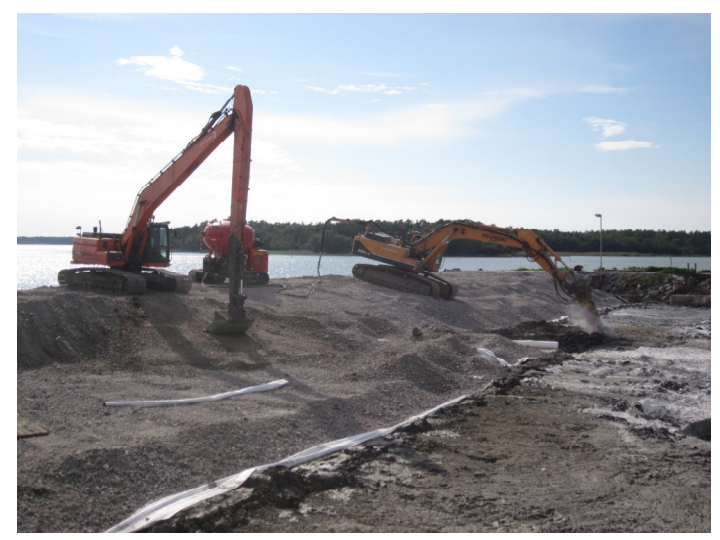

Fig. 5. Mass stabilization of dredged sediments (silt, clay and mud) on going in Uusikaupunki in 2014. (Source: photo by Ari Mäkinen, Ramboll Finland Oy)

\section{Mass stabilization in road and railroad construction}

During the last 10-20 years mass and especially column stabilization methods have been used day-to-day basis in the infra construction of the soft Baltic Sea coastal clay areas and the interior peat, mud and clay areas in Nordic countries. Deep stabilization has mostly been used to reduce settlements of road and street embankments and municipal networks of water supply and sewerage. In some cases deep stabilization has been used to increase the global stability or to support excavations. 
The mass and column stabilization amounts (volumes) in Finland are presented in Figure 6. Mass stabilization has been used also in some projects in Baltic countries see presentation of projects of Kose-Mäo and Simuna.

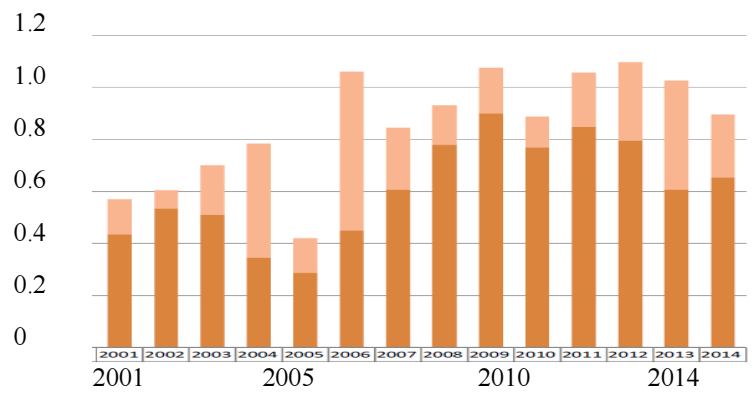

Fig. 6. The annual amounts of mass $(\square)$ and column ( $\square$ ) stabilization in Finland. The unit is million $\mathrm{m} 3$ of stabilized soil.

"Column stabilization" = "deep stabilization/mixing forming columns of stabilized soil” (Source: Kuusipuro 2015)

\section{Kose-Mäö-case, mass stabilization of road subsoil}

The E263 Tallinn-Tartu-Võru-Luhamaa highway with the total length of $288 \mathrm{~km}$ progresses toward the southeast from Tallinn to the Russian border. Road section at Kose-Mäo $(\approx 40 \mathrm{~km})$ is partly designed to be built on a soft soil area where the soft soil (mainly peat) must be either improved with mass stabilization, mass replaced or a synthetic georeinforcement must be used to ensure better stability and bearing capacity under the road embankment. In the case of mass stabilization, the amount of stabilized peat can be as much as $0.2-0.3$ million $\mathrm{m}^{3}$ (Forsman et al. 2009).

The average thickness of peat layer is $\approx 2.7 \mathrm{~m}(2.5-$ $3 \mathrm{~m})$ at the test area. Peat is mainly medium decomposed (water content 760-930\%) and the shear strength is $\approx 5 \mathrm{kPa}$ under the surface layer. Mass stabilization field tests have been carried out in 2009 and the longterm behaviour has been studied with new soundings in
2015. The stabilization was done using Portland cement and two different types of fly ash as binder mixtures. Mass stabilization field test was done in 01-02/2009. The target shear strength of $50 \mathrm{kPa}$ has been achieved in 0.5-2 months after stabilization in 2009 at all of the eight test areas. The realized strength was 2-3 times over the target strength in some areas. The strength increase between soundings of 2009 and 2015 has been highest at the area where the binder was cement+fly ash $\left(70+100 \mathrm{~kg} / \mathrm{m}^{3}\right.$ - peat $)$. The lowest increase of strength was found to be at the areas where pure cement $\left(250 \mathrm{~kg} / \mathrm{m}^{3}\right.$ - peat) was used (Fig. 7) (Forsman et al. 2015c).

Embankment and settlement plates were installed after the mass stabilization in $2 / 2009$. Levels of the plates have been observed over the time, frequently during the first year. The most recent observation was in $11 / 2015$. No settlement has been observed after 2009 . The average thickness of the embankment over mass stabilization is about $1.5 \mathrm{~m}$.

\section{Simuna case, mass stabilization of a road}

The Simuna-Vaiatu project encompasses the testing of two different technologies of using oil shale ash in road construction - 1) layer stabilization with coarse materials on road base and 2) mass stabilization of peat on weak surfaces before road construction. Test sites are located on state owned road nr 17192 Simuna-Vaiatu, Estonia. Mass stabilization of peat and other unstable surfaces was tested on a $500 \mathrm{~m}$ long road section. Each $100 \mathrm{~m}$ section was built with different binder recipes, i.e. with different ash-cement ratio. The construction stages included the removal of the old surface and mass stabilization of peat, followed by construction of embankment, road course and pavement on a stabilized peat layer. The stabilization works were made in 20132014. Peat properties were: $\mathrm{w}=350-750 \%, \mathrm{pH}=4.1-$ 7.2 and loss of ignition 58-88 \% (LIFE 2015).

Area 4:

Soundings

$11 / 2015$

$\approx 6.5$ years after

mass stabilization

Soundings
$3-4 / 2009$
$\approx 3$ months after
mass stabilization

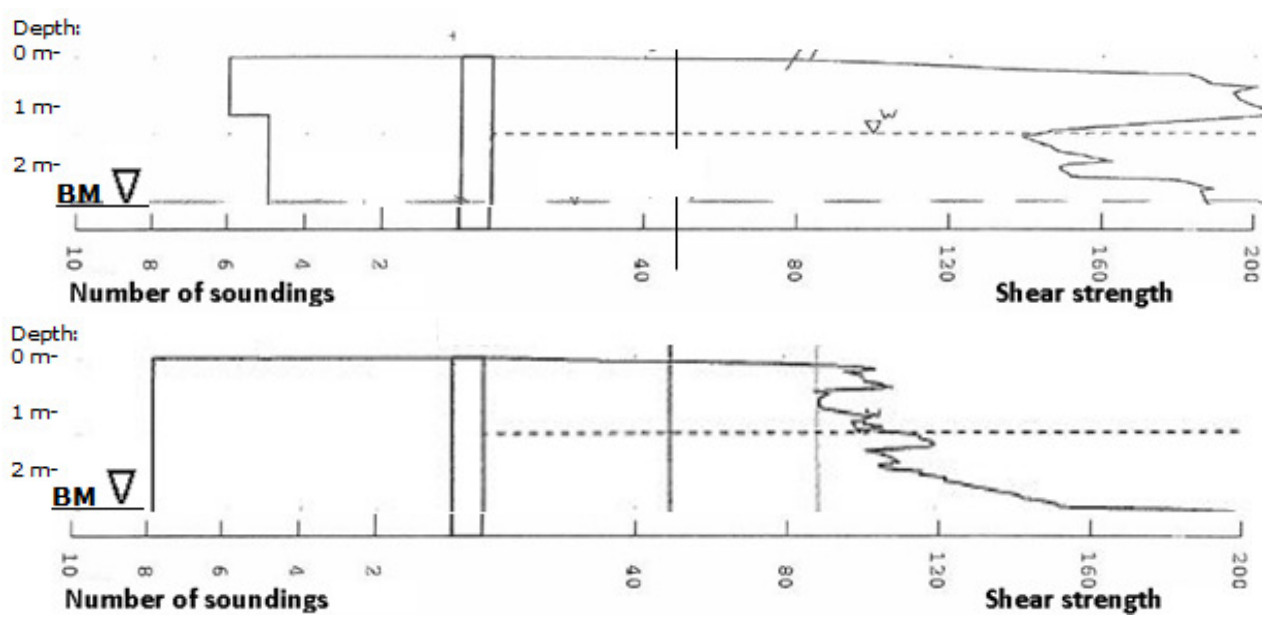

Fig. 7. Kose-Mäo test stabilization. The average shear strength of mass stabilized peat after 3 months and after 6 years of stabilization. The used binder was cement + ash $70+200 \mathrm{~kg} / \mathrm{m}^{3}$. The sounding method is "column sounding" (Forsman et al. 2015c) 
Binder material usage in general was oil shale ash + cement $\left(170-200+60-110 \mathrm{~kg} / \mathrm{m}^{3}-\right.$ peat $)$. The codes of oil shale ash were "EF CFB" and "EF PF". The targeted shear strength for stabilized peat was $50 \mathrm{kPa}$ and mostly it was easily exceeded. The strength of the stabilized peat increased between the first and the second quality control soundings like it was in the case of Kose-Mäo with OSA-binder. In Simuna case the amount of binder material per unit $\left(\mathrm{kg} / \mathrm{m}^{3}\right)$ was rather large. It is possible to decrease the unit amount of binder material in future projects to save cost and time of the work process. (LIFE 2015; Ronkainen et al. 2013)

\section{Conclusions}

The application of mass stabilization techniques alters the technical and environmental properties of soft soil in a way that makes it possible to construct on top of the stabilized soil or utilize it as a construction material (filling or embankment).

Mass stabilization is also a feasible method for the stabilization of contaminated sediments which allows the utilization of stabilized sediments. Feasibility and cost benefit, in the case of the utilization of stabilized sediments, is easily proved in harbour construction projects where the need of natural resources would otherwise be enormous.

The most commonly applied binder in stabilization has so far been cement. However, its high price and its considerably high carbon footprint encourage searching for alternative solutions. Various industrial by-products are applicable in binder mixtures. The replacement of cement with binders based on fly ash or oil shale ash in the stabilization of dredged sediments has been studied widely both in the laboratory and on the site. These products make the method more economic and environmental friendly. The environmental acceptability is evaluated by testing leaching of contaminants from the stabilized material in the laboratory. The results of the tests provide good reasons for the use of fly ash based binders in the process of stabilization of dredged sediments.

Several applications for the utilization of stabilized sediments have already been developed but it is still possible to find new potential applications. So far, the knowledge of the environmental authorities regarding the environmental advantages of the method has been increasing. There have been cases in Finland where the use of the mass stabilization method for the treatment of the sediments was a precondition to the fulfilment of a project.

Mass stabilization equipment is currently technically on a high level. The equipment is mobile and therefore easy to use in various locations. Mass stabilization method has been implemented in numerous countries (at least 25-30 countries) in various infrastructure and environmental engineering applications, proving it to be an economical and eco-efficient solution.

\section{Acknowledgements}

We express our gratitude to all numerous clients who are using mass stabilization technology in numerous applications and that way are developing the methods.

\section{Funding}

The Funding of this article is by Ramboll Finland Oy.

\section{Disclosure statement}

Authors do not have any competing financial, professional, or personal interests from other parties.

\section{References}

Autiola, M.; Reinikainen, S.-P.; Kohonen, J.; Sirén, H.; Marjamäki, T.; Kangaskolkka, M.; Lindroos, N.; Lahtinen, P.; Tiikerpuu, L.; Lampinen, T.; Kalliokoski, V.; Vierimaa, M. 2012. SMOCS (Sustainable Management of Contaminated Sediments in Baltic Sea Region), Field test in Port of Kokkola, Finland. Lappeenranta University of Technology, Faculty of Technology, LUT.

Forsman, J.; Jyrävä, H.; Lahtinen, P.; Niemelin, T.; Hyvönen, I. 2015a. Mass stabilization manual [online], [cited 25 April 2016]. Available from Internet: http://www.uuma2.fi

Forsman, J.; Lindroos, N.; Korkiala-Tanttu, L. 2015b. Three mass stabilization phases in the west harbor of Helsinki, Finland - geotechnical and environmental properties of mass stabilized dredged sediments as construction material, in Deep Mixing 2015 Conference, 2-5 June 2015, San Francisco, United States, 671-680.

Forsman, J.; Piispanen, P.; Winqvist, F. 2015c. Kose-Mäo test stabilization 2009, compression tests 11/2015 (column penetration soundings, report). Client Maanteeamet, 11 November 2015, Espoo.

Forsman, J.; Hakari, M.; Jyrävä, H.; Ritsberg, K.; Skepast, P. 2009. Mass stabilization of E263 highway section Kose - Mäo in Estonia, in XXVII International Baltic Road Conference, 24-26 August 2009, Riga, Latvia.

Havukainen, J.; Leppänen, M.; Piispanen, A. 2011. Stabilization of TBT-sediment in a harbour in Helsinki. Published in Ground Improvement (ICE), UK.

Kuusipuro, K. 2015.The annual amount of deep mixing in Finland. PP-presentation. 27 August 2015, Espoo (in Finnish).

Lahtinen, P.; Niutanen, V. 2009. Development of in-situ mass stabilization technique in Finland, in Deep Mixing 2009 Okinawa Symposium, 19-21 May 2009, Okinawa, Japan.

LIFE. 2015. Osamat applications, piloting and verification actions simuna-vaiatu pilot report. LIFE+09/ENV/ 227.

Lindroos, N.; Ronkainen, M.; Autiola, M.; Lahtinen, P.; Forsman, J.; Leppänen, M. 2014. Mass stabilization of contaminated sediments. Bergmekanikk/Geoteknikk, Oslo.

Lindroos, N.; Lahtinen, P.; Autiola, M.; Reinikainen, S.-P.; Kohonen, J.; Lampinen, T. 2012. Stabilization Studies 
for Contaminated Sediments from Baltic Sea Area Case SMOCS, in WASCON 2012, 30 May - 1 June 2012, Gothenburg, Sweden.

Maijala, A.; Forsman, J.; Lahtinen, P.; Leppänen, M.; Helland, A.; Håфya, A.-O.; Konieczny, M. 2009. Binders, methods and techniques to stabilize/solidify polluted soil and sediment. Ramboll Norege AS.
Ronkainen, M.; Pototski, A.; Puhkim, H.; Lahtinen, P.; Niemelin, T. 2013. OSAMAT - utilization of oil shale ashes in road construction, in The XXVIII International Baltic Road Conference, 26-28 August 2013, Vilnius, Lithuania.

SMOCS. 2013. Sustainable Management of Contaminated Sediments, Guideline”. 82 p. 